\title{
The efficacy of P.O.P. on Teen violence and the anti-violence programing in Northwest Indiana and greater Chicagoland area
}

\author{
Isaiah Sloss, Chiamara Anokwute, Michael McGee MD, Reuban Rutland MD \\ Indiana University School of Medicine Northwest - Gary
}

\section{Background:}

Fights, bullying, and gun violence in the Northwest Indiana and Chicagoland middle schools and high schools can have long lasting effects on a student's physical, emotional, or mental wellbeing. Project Outreach and Prevention on Youth Violence (henceforth POP) is a foundation started by two NWI doctors, Dr. Michael McGee and Dr. Reuban Rutland, looking to do their part in preventing victims of youth violence from reaching their emergency departments.

POP also reaches students underrepresented in medicine to breach that gap. Programs such as POP's Health Professions Enrichment Program (HPEP). POP also utilizes school rallies and violence prevention seminars throughout the year to reach at risk youth. Activities at these rallies include Stop the Bleed training, where students are trained and certified by professionals on how to stop a bleed to various parts of the body. POP also utilizes local celebrities, artists, public figures, and community leaders to incentivize the participation of their target population.

Does implementation of anti-violence events with school age students by professionals and community leaders decrease incidences of violence or increase interest in college/STEM professions?

\section{Hypothesis:}

- There is an increase in the interest in college/STEM professions.

- There is a decrease in incidences of violence at schools with active SAVE chapters or participating in an anti-violence event.

\section{Experimental Design or Project Methods:}

Surveys, Observations, Student Interviews, Intervention, Cohort Study, Program evaluations, Longitudinal Study (Go to each school nearby and request the info)

The study's population includes students from 7th grade through high school seniors located throughout 13 schools in the northwest Indiana region. POP

\section{Results:}

Analyze Survey Data and interviews for positive correlation with the data.

\section{Conclusion/Potential Impact:}

Pending Review; The potential impact this project yielding positive results would help demonstrate efficacy of POP and enable us to seek more funding opportunities and implement these programs on a wider scale and hopefully being able to see lower instances of violence in areas where programing takes place. 